\title{
Analysis of histamine as a hair-cell transmitter in the lateral line of Xenopus laevis
}

\author{
Sanford C. Bledsoe, Jr., Robert J. Sinard and Susan J. Allen \\ Kresge Hearing Research Institute, University of Michigan Medical School, Ann Arbor, Michigan, U.S.A.
}

(Received 22 June 1988; accepted 22 October 1988)

\begin{abstract}
The actions of histamine and histamine antagonists on afferent nerve activity were investigated in the lateral line of Xenopus laevis. Histamine $(0.002-2.0 \mathrm{mM})$ had no effect on spontaneous activity or excitatory responses to water motion. In contrast, pyrilamine, an $\mathrm{H}_{1}$ receptor antagonist, suppressed spontaneous activity beginning at $0.01-0.05 \mathrm{mM}$. Below $0.3 \mathrm{mM}$ the suppression was often preceded by a small excitatory response and responses to high (24-30 dB re threshold), but not low (0-18 dB) levels of water motion were selectively suppressed. Higher concentrations (0.3-2.0 $\mathrm{mM})$ abolished spontaneous activity and suppressed responses at all levels of water motion. Cimetidine, an $\mathbf{H}_{2}$ receptor antagonist, had similar actions but was one-tenth as potent as pyrilamine. Tetrodotoxin $(0.001-0.1 \mu \mathrm{M})$, which blocks voltage-sensitive $\mathrm{Na}^{+}$channels, mimicked the suppressive effects of the histamine antagonists. Histamine $(2.0 \mathrm{mM})$ failed to block the actions of pyrilamine $(0.1 \mathrm{mM})$ indicating its effects are mediated through a mechanism other than histamine receptors. In addition, pyrilamine $(0.05-0.1 \mathrm{mM})$ non-selectively suppressed excitation to exogenously applied L-glutamate $(1.0-2.0 \mathrm{mM})$, L-aspartate $(1.0-2.0 \mathrm{mM})$, kainate $(0.005-0.01 \mathrm{mM})$, and quisqualate $(0.002-0.005$ $\mathrm{mM}$ ) and altered responses to $N$-methyl-D-aspartate $(0.5-1.0 \mathrm{mM})$. The results are inconsistent with histamine being a transmitter in the Xenopus lateral line and reveal that the actions of histamine antagonists are nonspecific, possibly due, in part, to blockade of voltage-sensitive $\mathrm{Na}^{+}$channels.
\end{abstract}

Lateral line; Hair-cell transmitter; Histamine; Pyrilamine; Glutamate; Tetrodotoxin

\section{Introduction}

The identity of the primary afferent transmitter released by hair cells in octavolateralis organs, including the amphibian lateral line, is not known, though evidence suggests that it is an excitatory amino acid, possibly L-glutamate (Bobbin et al., 1985b; Bledsoe, 1986; Bledsoe et al., 1988). Recently, Guth and associates (Norris et al., 1987) suggested that histamine may play a role as a hair-cell transmitter in the semicircular canal of the frog. They based this conclusion on the finding that sub-millimolar amounts $(0.001-0.1 \mathrm{mM})$ of histamine excite canal afferent nerve fibers. In addition, $\mathrm{H}_{1}$ and $\mathrm{H}_{2}$ receptor blocking agents

Correspondence to: Dr. Sanford C. Bledsoe, Jr., Kresge Hearing Research Institute, University of Michigan Medical School, 1301 E. Ann Street, Ann Arbor, MI 48109-0506, U.S.A. were reported to suppress canal spontaneous and evoked activity at concentrations as low as 0.01-0.05 mM. In the present study we examined the effects of histamine and histamine receptor antagonists on the lateral line of Xenopus laevis to explore further the role of histamine as a transmitter at a hair cell-afferent nerve synapse. A preliminary report has been presented (Bledsoe and Sinard, 1987).

\section{Methods}

Experiments were performed on adult male or female African clawed frogs, Xenopus laevis. The techniques for removing a portion of skin containing the lateral line and isolating a single end-organ (stitch) and the in vitro methods for recording afferent nerve activity and applying drugs to the inner, serosal surface of the skin were as previously described (Bledsoe and Bobbin, 1982; Bled- 
soe et al., 1983). Isolated skins were held on the end of a plastic cylinder with a Neoprene O-ring with the external, cupular surface of the skin facing down into a water-filled chamber. The posterior lateralis nerve trunk was dissected free from connective tissue on the serosal surface and action potentials from the two afferent nerve fibers innervating a selected stitch were recorded extracellularly with a suction electrode, digitized and counted with a rate-meter in 5- or 30-s time bins. The inner surface of the skin was continuously washed with a frog Ringer solution at room temperature $\left(20-23^{\circ} \mathrm{C}\right)$ except during periods of drug testing. The Ringer solution, which flowed through the experimental chamber at a rate of $2 \mathrm{ml} / \mathrm{min}$, had the following composition $(\mathrm{mM}): \mathrm{NaCl}, 110$; $\mathrm{KCl}, 2.0 ; \mathrm{CaCl}_{2}, 1.8 ; \mathrm{Na}_{2} \mathrm{HPO}_{4}, 2.25 ; \mathrm{NaH}_{2} \mathrm{PO}_{4}$, $0.75 ; \mathrm{pH}, 7.0$. Drugs were dissolved in this solution and the $\mathrm{pH}$ adjusted with $\mathrm{NaOH}$.

Histamine and other drugs were tested for agonist activity as previously described (Bledsoe et al., 1983). They were applied in a $50 \mu 1$ volume to the serosal surface of the stitch from a micropipette. The Ringer wash was turned off and the remaining fluid on the skin aspirated $3 \mathrm{~min}$ before drug application. Drugs were permitted to stay in contact with the stitch for $7 \mathrm{~min}$ before turning the wash back on. The preparations were washed for at least $30 \mathrm{~min}$ between applications of histamine to minimize the tolerance to histamine reported by Norris et al. (1987). As a control for mechanical scnsitivity, drug-free Ringer solution was applied at least once on all preparations. Each experiment began by applying $2.0 \mathrm{mM}$ L-glutamate to assess the ability of the preparation to respond to exogenously applied drugs. In seven histamine experiments spontaneous activity was recorded in 30-s time bins; in 2 experiments 5-s bins were utilized. Norris et al. (1987) reported that the excitatory response to histamine was transitory, lasting for $2-3 \mathrm{~min}$. Thus, to quantify potential changes in nerve activity produced by histamine, mean discharge rates were calculated from $1 \mathrm{~min}$ of activity recorded immediately prior to the application of histamine and from the same period of time beginning $1 \mathrm{~min}$ after the application. The mean post-drug discharge rate was then expressed as a percentage of the pre-drug level. Spiking activity was continuously monitored on a loudspeaker in every experiment to minimize further the possibility of missing any transitory changes produced by histamine.

To study the effects of histamine antagonists on responses to excitatory amino acids, excitant responses were obtained during an initial drug-free Ringer wash, $20 \mathrm{~min}$ after applying a $200 \mu \mathrm{l}$ volume of antagonist and again 20-30 min after washing the preparation with drug-free Ringer solution. The $3 \mathrm{~min}$ of activity before each amino acid application was used to calculate a mean spontaneous firing rate. The difference between the peak excitation elicited by an amino acid and the pre-agonist spontaneous level in the presence of the histamine antagonist was expressed as a percentage of that obtaincd in its absence.

The effects of drugs on water motion-induced responses were evaluated as previously described (Bledsoe et al., 1985; Bobbin et al., 1985a). A glass rod attached to the cone of a loudspeaker was placed in the water bathing the external surface of the skin. It was positioned $0.5-1.0 \mathrm{~mm}$ beneath a selected stitch and vibrated at a frequency of 35 $\mathrm{Hz}$ with a sinusoidal voltage. A microcomputer controlled stimulus on, off and magnitude. Stimulus magnitude was expressed in $\mathrm{dB}$ relative to the threshold of excitation. Threshold was established with audiovisual cues and defined as the intensity needed to produce a just detectable increase in spontaneous discharge rate. A sequence of responses to increasing magnitudes of water motion was obtained by alternately recording $15 \mathrm{~s}$ of stimulated and spontaneous activity in $5 \mathrm{~s}$ time bins. The magnitude of water motion was increased from threshold $(0 \mathrm{~dB})$ over a $30 \mathrm{~dB}$ range in $6 \mathrm{~dB}$ increments and responses were obtained twice at each level of stimulation. To avoid mechanical artifacts induced by the flow of fluid through the chamber, the stimulated-spontaneous sequence was recorded with the Ringer wash turned off. During testing, the sequence was obtained in the presence of $200 \mu l$ of drug-free Ringer's (control), 15-20 min after exchanging the $200 \mu \mathrm{l}$ of Ringer's for a $200 \mu \mathrm{l}$ volume of drug and again 20-30 min after washing the preparation with drug-free Ringer solution. In some experiments, drugs were applied in a cumulative manner at successively higher concentrations without intervening drug-free Ringer wash. 
Stimulus-response curves were derived from the stimulated-spontaneous sequence by calculating mean stimulated and spontaneous discharge rates using the spike counts in the second and third $5 \mathrm{~s}$ time bins from each of the 2 samples of stimulated and spontaneous activity. The difference between the mean stimulated discharge rate at a given intensity and the mean spontaneous rate for the corresponding period of spontaneous activity was defined as a driven response. Responses at each level of water motion were expressed as a percentage of the maximum driven response obtained in the presence of drug-free Ringer solution.

The compounds utilized, and their sources, were the following: L-glutamic acid (monosodium salt); L-aspartic acid (monosodium salt); kainic acid; cimetidine; pyrilamine (maleate salt); histamine dihydrochloride; tetrodotoxin (all from Sigma); $N$-methyl-D-aspartic acid and quisqualic acid (from Tocris).

\section{Results}

In a total of 9 experiments histamine failed to alter afferent nerve spontaneous activity at concentrations between 0.002 and $2.0 \mathrm{mM}$. Fig. 1 depicts results from one experiment. The small changes in discharge rate occurring after the applications of histamine in this and all other preparations were no different than those produced by control applications of drug-free Ringer solution. For example, in Fig. 1, there was a $5.0 \%$ increase in discharge rate from pre-drug levels one min after the application of $0.002 \mathrm{mM}$ histamine. A $4.0 \%$ increase occurred following the application of Ringer solution alone (data not shown). In seven experiments in which afferent nerve activity was recorded in 30-s time bins, the mean percent change in discharge rate produced by histamine at $0.002,0.02$ and $2.0 \mathrm{mM}$ was $+1.6 \pm 2.1,+1.3 \pm$ 2.9 and $-0.5 \pm 2.8 \%$, respectively (mean \pm S.E., $N=7$ ). Paired $t$-test analysis revealed that none of these changes were significantly different from those produced by the Ringer controls $(+1.0 \pm$ $2.5 \%$; mean \pm S.E., $N=7$ ). Results from 2 experiments using 5-s time bins and a second bottle of histamine bearing a different lot number also revealed no effect of the drug on lateral-line activity. The lack of effect of histamine was not due to the

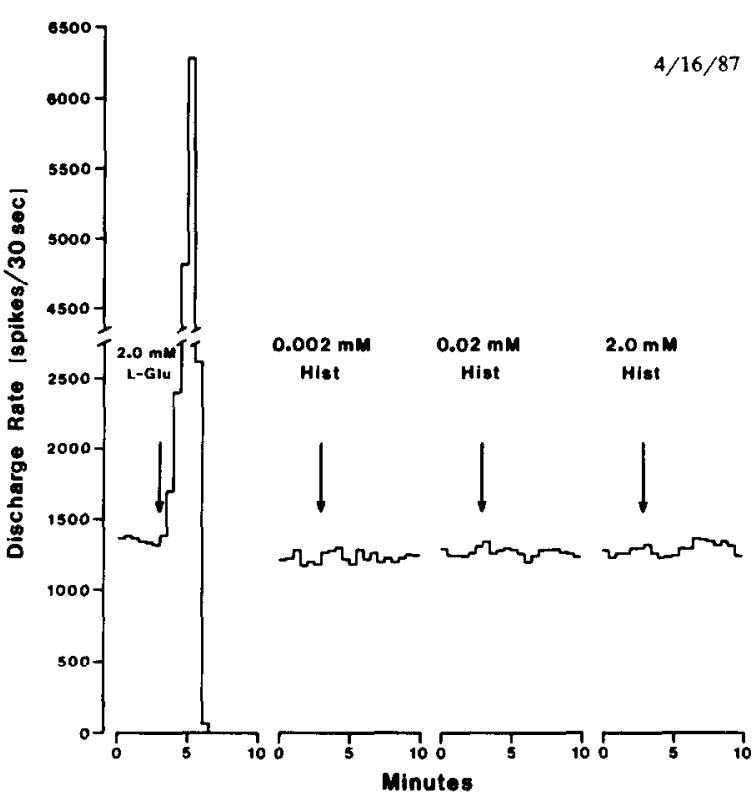

Fig. 1. Lateral line afferent nerve fiber responses illustrating the lack of effect of $0.002-2.0 \mathrm{mM}$ histamine (Hist) on spontaneous activity in a preparation that responded to $2.0 \mathrm{mM}$ L-glutamate ( $\mathrm{L}-\mathrm{Glu}$ ). The data was collected in $30 \mathrm{~s}$ time bins and the arrows indicate $50 \mu 1$ of drug application to the serosal surface of the stitch from a micropipette. The drug-free Ringer wash was turned off $3 \mathrm{~min}$ before the indicated time of each drug application. Drugs were permitted to remain in contact with the skin for 7 min before turning the wash back on for 30 min (wash data not shown).

experimental conditions since in each of the preparations a test dose of L-glutamate $(2.0 \mathrm{mM})$ produced strong excitation followed by post-excitatory suppression (Fig. 1). Histamine also failed to alter responses to water motion at concentrations of $0.02 \mathrm{mM}(N=3)$ and $2.0 \mathrm{mM}(N=5)$. Fig. 2 graphically depicts the lack of effect of 2.0 $\mathrm{mM}$ histamine on stimulus-response curves obtained at several magnitudes of water motion. From these results (Figs. 1 and 2) it can be appreciated that histamine exerts no measurable effect on synaptic transmission in the Xenopus lateral line.

In contrast, pyrilamine, an $\mathrm{H}_{1}$ receptor antagonist, suppressed spontaneous activity at concentrations beginning as low as $0.01-0.05 \mathrm{mM}$. In 11 out of 17 experiments, pyrilamine had a small excitatory effect at concentrations below $0.1 \mathrm{mM}$ (Fig. 3 ). This changed to suppression at higher concentrations (Fig. 3) with abolishment of sponta- 


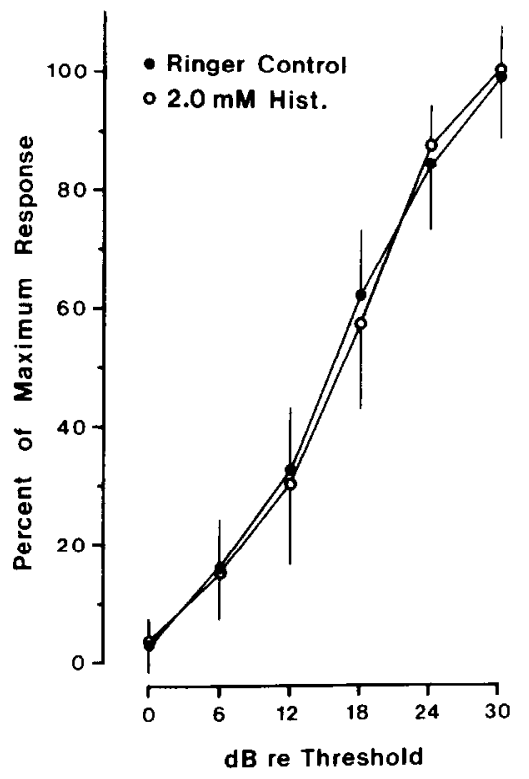

Fig. 2. Stimulus-response curves to increasing magnitudes of water motion in the presence of Ringer solution (filled circles) and $2.0 \mathrm{mM}$ histamine (open circles). The curves were derived from $15 \mathrm{~s}$ samples of stimulated and spontaneous activity alternately recorded in $5 \mathrm{~s}$ time bins as described in Methods. Data points represent mean values from 5 experiments and are expressed as a percentage of the maximum driven response obtained in the presence of drug-free Ringer solution. Vertical bars denote standard deviations of the means.

neous activity occurring between 0.3 and $2.0 \mathrm{mM}$. Across preparations the concentration of pyrilamine that produced a $50 \%$ suppression of spontaneous activity $\left(\mathrm{EC}_{50}\right)$ ranged from 0.05 to $0.5 \mathrm{mM}$ with a mean $\mathrm{EC}_{50}$ value of $0.165 \mathrm{mM}$. The effects of pyrilamine were reversible after washing with drug-free Ringer solution; however, only partial recovery occurred following prolonged exposure to high concentrations of the drug $(0.5-2.0 \mathrm{mM})$. In 3 experiments the suppression induced by pyrilamine $(0.1 \mathrm{mM})$ was not blocked by $2.0 \mathrm{mM}$ histamine (Fig. 4) indicating that the actions of pyrilamine are mediated through a mechanism other than histamine receptors.

Pyrilamine was tested for effects on water motion-induced excitation of afferent nerve fibers in 10 experiments at concentrations between 0.02 and $2.0 \mathrm{mM}$. In 5 of the experiments pyrilamine was applied in a cumulative manner from 0.02 $\mathrm{mM}$ to $2.0 \mathrm{mM}$ without intervening Ringer wash.
At concentrations that suppressed spontaneous activity up to $90 \%$, pyrilamine markedly suppressed responses to high levels of water motion (24-30 dB re threshold) while responses to low levels of stimulation were slightly suppressed (< $10 \% ; N=2$ ), unaffected ( $N=3$ ) or enhanced (up to $21 \% ; N=5$ ). Owing to the variable sensitivity of individual preparations to pyrilamine, it was not possible to pool data at a given concentration across experiments. However, the results depicted in Fig. 5 are representative of the findings. In the presence of $0.1 \mathrm{mM}$ pyrilamine the initial spontaneous discharge rate is decreased $40 \%$. Comparing the stimulated responses in Fig. 5 in the presence of $0.1 \mathrm{mM}$ pyrilamine to the corresponding ones in the Ringer control reveals that the response at $30 \mathrm{~dB}$ is decreased $26 \%$ whereas those at $0,6,12$,

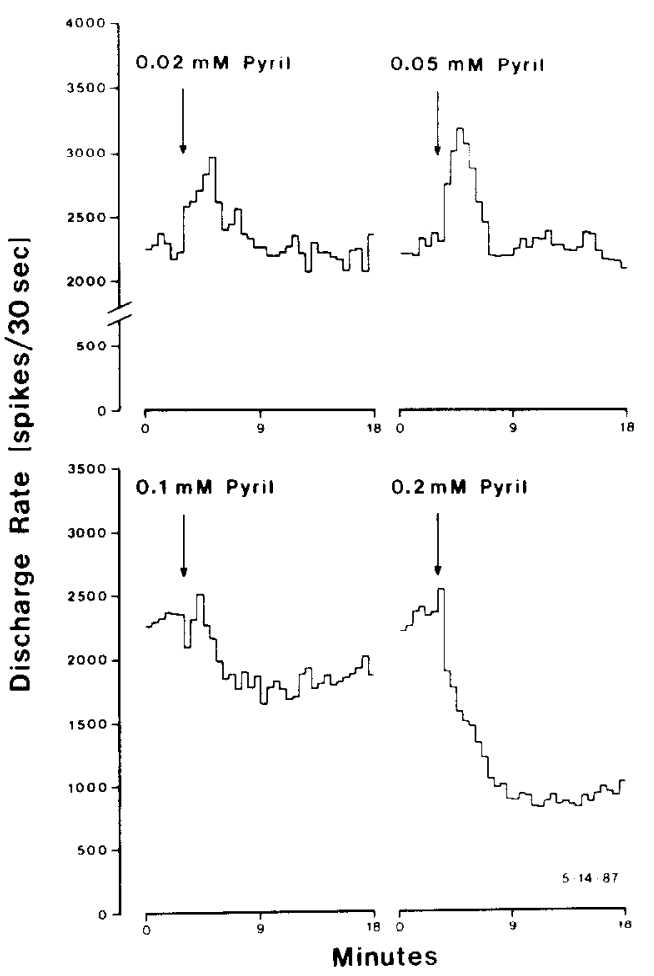

Fig. 3. Lateral line afferent nerve fiber responses to varying concentrations of pyrilamine (Pyril) showing that low concentrations $(0.02-0.05 \mathrm{mM})$ are excitatory to spontaneous activity, while high concentrations $(0.1-0.2 \mathrm{mM})$ are suppressive. Arrow designation and experimental protocol as in Fig. 1 except that a $200 \mu \mathrm{l}$ volume of pyrilamine was applied and remained in contact with the skin for $15 \mathrm{~min}$ before turning the

Ringer wash back on for $20 \mathrm{~min}$ (wash data not shown). 


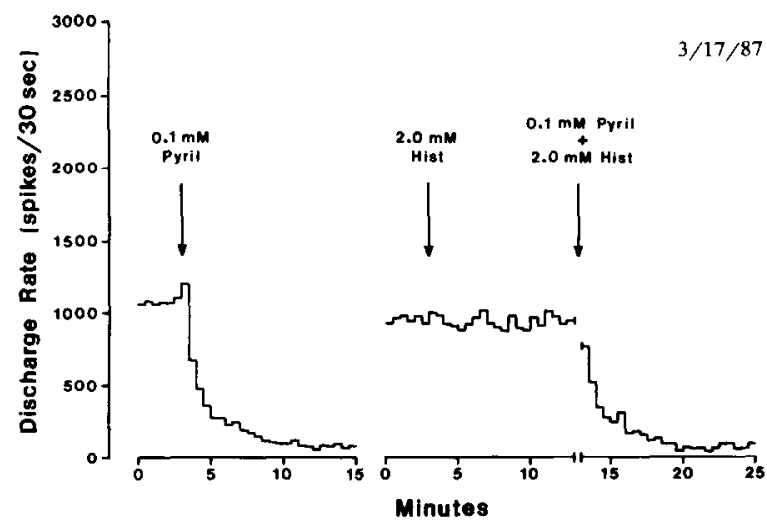

Fig. 4. Lateral line afferent nerve fiber responses to $0.1 \mathrm{mM}$ pyrilamine (Pyril) in the absence (left panel) and presence (right panel) of $2.0 \mathrm{mM}$ histamine (Hist), illustrating that histamine does not block the suppression to pyrilamine. Arrow designation and experimental protocol as in Figs. 1 and 3 except that in the right panel the $200 \mu 1$ of histamine was exchanged after $10 \mathrm{~min}$ for $200 \mu \mathrm{l}$ of histamine plus pyrilamine. There was a $30-s$ break in the recording during this exchange due to an electrical artifact induced by the pump used to aspirate histamine from the experimental chamber. Pyrilamine remained in contact with the skin for $12 \mathrm{~min}$ in each panel and the preparation was washed for $20 \mathrm{~min}$ after the first application (wash data not shown).

18 and $24 \mathrm{~dB}$ are increased $3,8,14,8$ and $19 \%$, respectively. At $0.3 \mathrm{mM}$ pyrilamine the initial spontaneous rate is decreased $90 \%$ and a comparison of the stimulated responses to the control reveals that at 18,24 and $30 \mathrm{~dB}$ the responses are decreased 10,45 and $63 \%$, respectively; whereas those at 0,6 and $12 \mathrm{~dB}$ are only slightly decreased (up to 5\%). The enhancement of low-level responses seemed to be concentration dependent and occurred most frequently between 0.05 and $0.3 \mathrm{mM}$ in experiments in which pyrilamine was applied in a cumulative manner. Water motion-induced responses were markedly suppressed at all levels of stimulation only at concentrations that abolished spontaneous activity (Fig. 5).

In 4 experiments cimetidine, an $\mathbf{H}_{2}$ receptor antagonist, had similar suppressive actions on spontaneous and evoked activity but was judged to be one-tenth as potent as pyrilamine (Fig. 6). In the results depicted in Fig. 6, $2.0 \mathrm{mM}$ cimetidine decreased the initial spontaneous rate $17 \%$. The stimulated response at $30 \mathrm{~dB}$ is decreased $37 \%$ whereas those at 0 to $24 \mathrm{~dB}$ are virtually unaf- fected or slightly increased (up to 7\%). At $5.0 \mathrm{mM}$ cimctidine, the initial spontaneous rate is decreased $40 \%$ and the responses at 24 and $30 \mathrm{~dB}$ are decreased 34 and $60 \%$, respectively. Those at lower levels of water motion are again little affected or slightly increased (up to $9 \%$ ). High concentrations (10 $\mathrm{mM})$ of cimetidine were required to abolish spontaneous activity and markedly suppress responses to water motion at all levels of stimulation (Fig. 6). In 3 experiments, tetrodotoxin (0.001-0.1 $\mu \mathrm{M})$, which blocks voltage-dependent $\mathrm{Na}^{+}$channels, mimicked the suppressive effects of pyrilamine and cimetidine on spontaneous activity and water motion-induced excitation (Fig. 7). Thus, comparing the stimulated responses in Fig. 7 in the presence of $0.005 \mu \mathrm{M}$ tetrodotoxin with the corresponding ones in the Ringer control reveals that at 0,6 and $12 \mathrm{~dB}$ the responses are increased 5,13 and $6 \%$, respectively; whereas, at 18,24 and $30 \mathrm{~dB}$ they are suppressed 25,41 and $45 \%$, respectively. Overall, the actions of pyrilamine, cimetidine and tetrodotoxin on water motion-induced excitation are suggestive of a use-dependent blockade (see Discussion).

Possible non-specific actions of pyrilamine werc examined by testing its ability to affect responses to excitatory amino acids. Compounds tested included kainate, quisqualate and $N$-methyl-Daspartate (NMDA) which are selective agonists for 3 subtypes of glutamate receptors which we have previously shown to be present in the Xenopus lateral line (Bledsoe et al., 1983). Pyrilamine (0.05-0.2 $\mathrm{mM})$ reversibly suppressed excitatory responses to L-glutamate at concentrations of Lglutamate $(1.0-2.0 \mathrm{mM} ; N=5)$ that produced strong excitation followed by post-excitatory suppression (Fig. 8). In the example depicted in Fig. 8 the excitation induced by L-glutamate is suppressed $91 \%$ by pyrilamine but the post-excitatory suppression appears unaffected. Similar effects were observed on responses to $L$-aspartate (1.0-2.0 $\mathrm{mM} ; N=2)$, quisqualate $(0.002-0.005 \mathrm{mM} ; N=$ 2) and kainate $(0.005-0.01 \mathrm{mM} ; N=3)$. Fig. 9 shows results for kainate in which pyrilamine reversibly suppressed the excitatory portion of the response $65 \%$ but did not affect the post-excitatory suppression. Excitatory responses to NMDA, which differ from those induced by non-NMDA agonists in the lateral line (Bledsoe et al., 1983), 


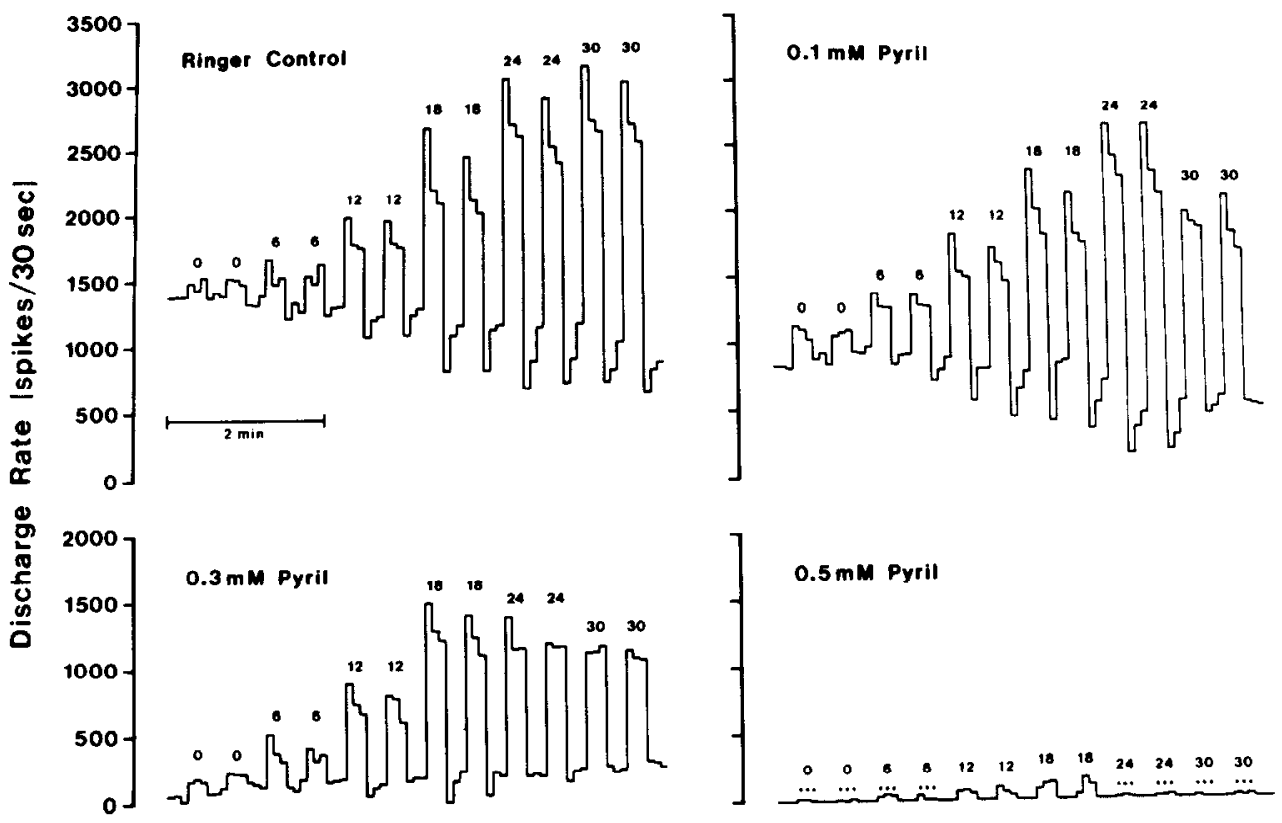

Fig. 5. Suppression of spontaneous activity and water motion-induced excitation of lateral line afferent nerve fibers by pyrilamine (Pyril). For the data designated Ringer control the drug-free Ringer wash was turned off and the remaining fluid on the serosal surface of the skin rapidly exchanged for a $200 \mu \mathrm{l}$ volume of fresh drug-free Ringer solution. An initial $15 \mathrm{~s}$ of spontaneous activity followed by alternating $15 \mathrm{~s}$ periods of stimulated and spontaneous activity were recorded in $5 \mathrm{~s}$ time bins. Numbers indicate magnitude of water motion in $\mathrm{dB}$ (re threshold). The data in the remaining panels were obtained in a cumulative manner by repeating the stimulated-spontaneous sequence 20 min after the $200 \mu 1$ of Ringer solution in the chamber was exchanged for $200 \mu 1$ containing pyrilamine at successively higher concentrations. Note, initial suppression occurs for responses to high levels of water motion (24-30 $\mathrm{dB}$ ) whereas low-level responses appear little affected or even enhanced until spontaneous activity is abolished (0.5 $\mathrm{mM})$.

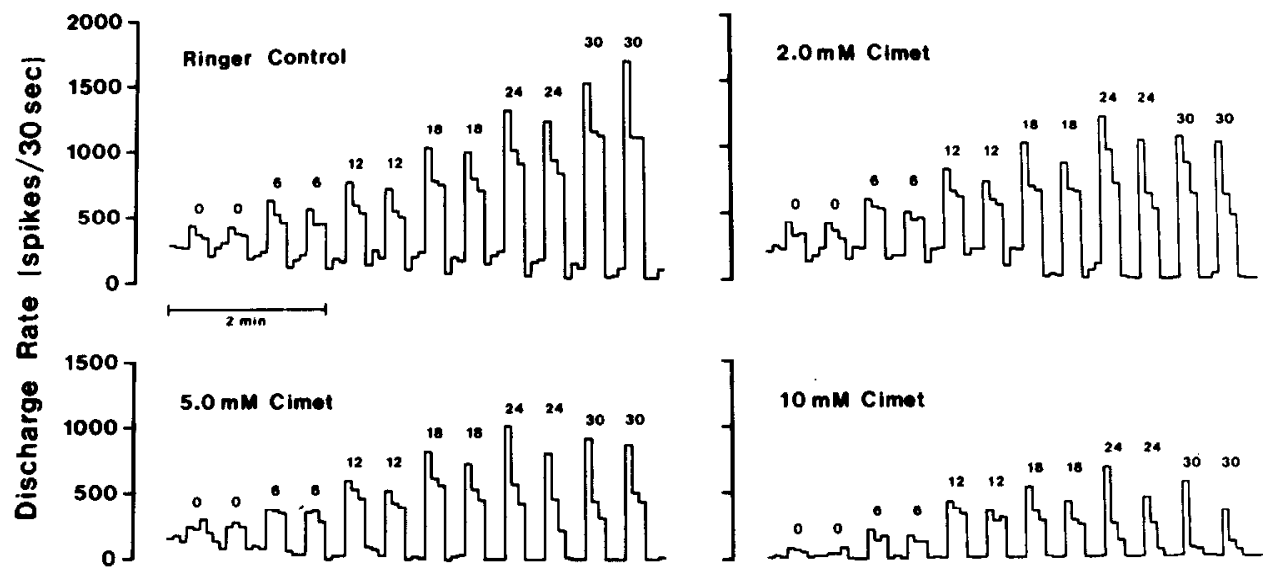

Fig. 6. Spontaneous activity and water motion-induced excitation of lateral line afferent nerve fibers in the absence and presence of cimetidine illustrating that cimetidine is less potent than pyrilamine (see Fig. 5). Experimental protocol and number designations as in Fig. 5. Note that the effects of cimetidine are similar to those of pyrilamine with the responses to high levels of water motion (24-30 dB) being suppressed more than the responses to low-level stimulation. 


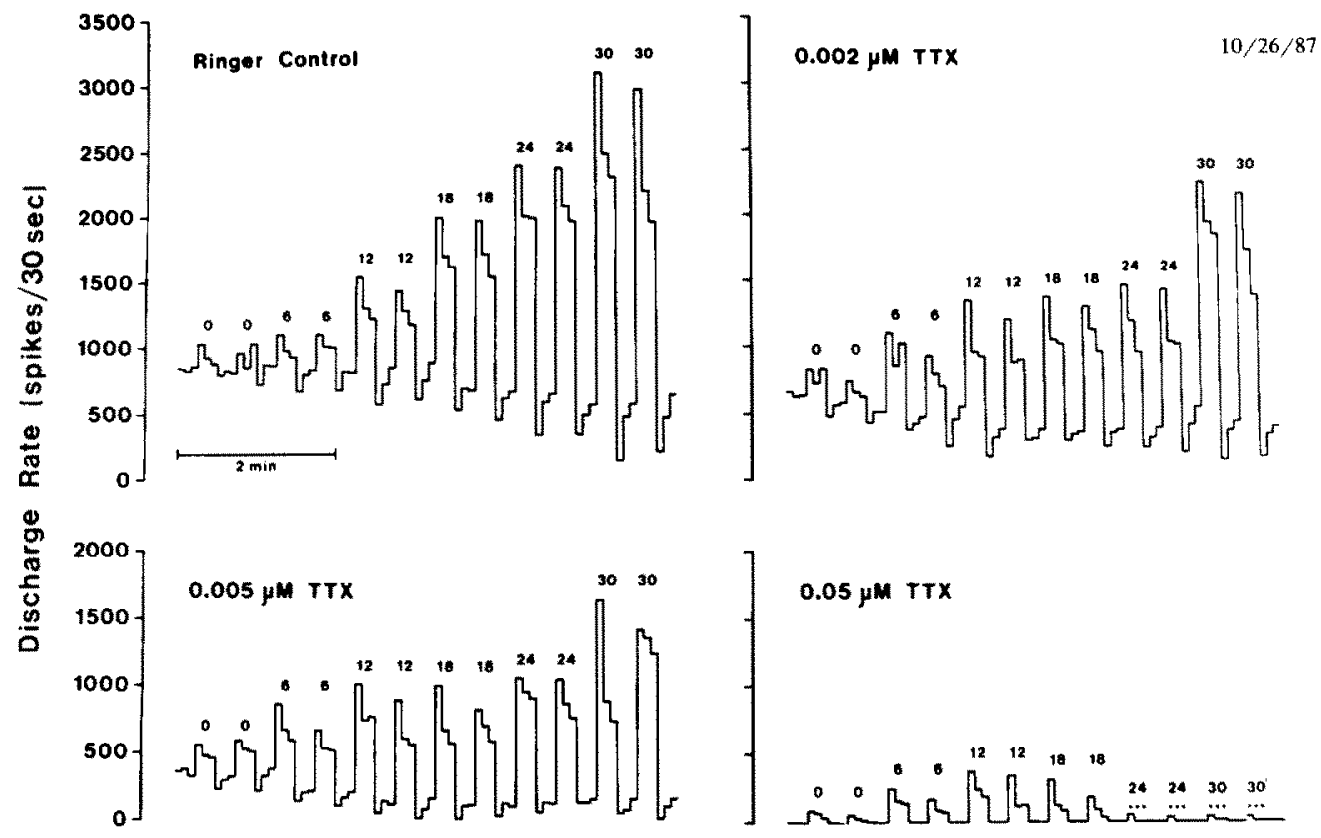

Fig. 7. Suppression of spontaneous activity and water motion-induced excitation of lateral line afferent nerve fibers by tetrodotoxin (TTX) at indicated concentrations. Experimental protocol and number designations as in Fig. 5 . Note that the effects on high- and low-level responses are similar to those produced by pyrilamine and cimetidine (see Figs. 5 and 6 ).

were reversed to inhibitory responses by pyrilamine in 3 of 4 experiments (Fig. 9).

Tetrodotoxin mimicked the suppressive effects of pyrilamine and cimetidine on responses to high concentrations $(1.0-2.0 \mathrm{mM})$ of L-glutamate. Thus, in 3 experiments (data not shown) tetrodotoxin (0.001-0.002 $\mu \mathrm{M}$ ) suppressed (up to $74 \%$ ) the excitatory portion of the glutamate response but did not prevent the post-excitatory suppression. In an additional 3 experiments, tetrodotoxin $(0.001$ $\mu \mathrm{M}$ ) suppressed (up to $60 \%$ ), but did not reverse, responses to NMDA $(1.0 \mathrm{mM})$.

L-Glutamate is a leading candidate for the excitatory transmitter released by hair cells in the Xenopus lateral line (Bledsoe et al., 1988). Thus, in view of the selective effect of pyrilamine on high but not low levels of water motion (Fig. 5), we further evaluated the effects of pyrilamine on near-threshold concentrations of L-glutamate. In contrast to the marked suppression of excitatory responses to L-glutamate at $1.0-2.0 \mathrm{mM}$, responses at $0.25-0.75 \mathrm{mM}$ were only slightly suppressed $(<15 \% ; N=7)$, unaffected $(N=7)$ or enhanced (up to 108\%; $N=5$ ) by pyrilamine $(0.05-0.1 \mathrm{mM})$. The enhancement was often accompanied by the emergence of post-excitatory suppression to L-glutamate (Fig. 10). Thus, the effects of pyrilamine on responses to L-glutamate appear similar to its effects on water motion-induced excitation.

\section{Discussion}

The results reveal that histamine has no effect on afferent nerve activity in the Xenopus lateral line. Spontaneous activity was neither increased nor decreased nor was there an alteration of responses to water motion. These findings contrast with those of Norris et al. (1987) who reported that histamine influenced nerve activity in the frog semicircular canal. At concentrations between 0.001 and $0.1 \mathrm{mM}$, histamine increased canal spontaneous activity while higher concentrations $(0.1-1.0 \mathrm{mM})$ produced suppression. Based on these actions, Norris et al. (1987) proposed histamine as a hair-cell transmitter candidate. The results of the present study, however, provide compelling evidence that histamine does not function as a neurotransmitter or modulator in the Xenopus lateral line. This is in agreement with the 


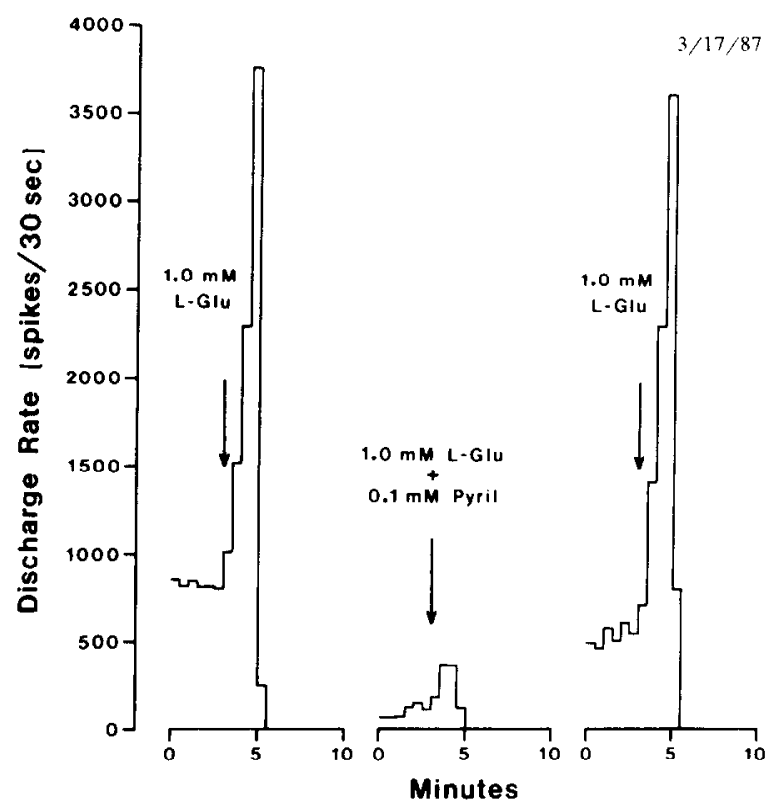

Fig. 8. Responses of lateral line afferent nerve fibers to exogenously applied $\mathrm{L}$-glutamate ( $\mathrm{L}-\mathrm{Glu}$ ) at $1.0 \mathrm{mM}$ in the absence and presence of $0.1 \mathrm{mM}$ pyrilamine (Pyril). Arrow designation and experimental protocol as in Fig. 1 except that $200 \mu 1$ of pyrilamine was added to the preparation $20 \mathrm{~min}$ before the indicated application of $\mathrm{L}$-glutamate plus pyrilamine. Response on the right was obtained after a $30 \mathrm{~min}$ drug-free Ringer wash. Data illustrate that the excitation to L-glutamate is suppressed while the post-excitatory suppression appears unaf fected.

report by Bobbin and Thompson (1978) which showed that histamine had little effect on soundevoked cochlear potentials in the guinca pig. Thus, if histamine plays a role in synaptic transmission in hair-cell systems, it does not appear to be a universal one.

In the lateral line, pyrilamine suppressed afferent nerve spontaneous activity and water motioninduced excitation beginning at $0.01-0.05 \mathrm{mM}$. Norris et al. (1987) also reported that the same concentrations of pyrilamine were effective in suppressing canal spontaneous and evoked activity. It should be noted, however, that cimetidine, an $\mathrm{H}_{2}$ receptor antagonist, was one-tenth as potent as pyrilamine in the lateral line, whereas Norris et al. (1987) reported cimetidine to be slightly more potent than pyrilamine in the semicircular canal. On face value, the greater potency of pyrilamine in the lateral line suggests that its actions are mediated selectively through $\mathrm{H}_{1}$ receptors. How- ever, two observations indicate this conclusion is unacceptable. First, and foremost, is the fact that histamine itself is inactive in the lateral line. Second, histamine failed to block the actions of pyrilamine. Thus, it is clear that pyrilamine must exert it effects on the lateral line through a mechanism other than blockade of histamine receptors.

In most systems, antihistamines are highly selective for histamine receptors at concentrations in the sub-nanomolar range (Taylor et al., 1982; Green, 1983; Borchard et al., 1986; Orsetti and Sorba, 1988). For example, studies on the binding of antihistamines to histamine receptors in the central nervous system have revealed a dissociation constant $\left(K_{\mathrm{B}}\right)$ for pyrilamine of $4 \times 10^{-10} \mathrm{M}$ (Green, 1983). However, it is well known that, in most preparations, antihistamines exhibit local anesthetic-like activity at low micromolar concentrations (Geller, 1981; Katayama and Tasaka, 1985). Thus, Geller (1981), studying the actions of histamine and histamine antagonists on cultured hypothalamic neurons demonstrated strong local anesthetic-like activity for diphenhydramine at concentrations above $0.01 \mathrm{mM}$. The molecular mechanism of action of local anesthetics is complex and varies slightly for different types of compounds (Strichartz, 1976). Nevertheless, the end result of local anesthetic action is to block nerve impulse conduction by preventing the influx of sodium ions through regenerative (voltage-dependent) $\mathrm{Na}^{+}$channels (Strichartz, 1976). Although the precise molecular mechanism of antihistamines is not known, their local anesthetic activity is generally attributed to a similar action on $\mathrm{Na}^{+}$ channels. In the present study, the suppressive effects of tetrodotoxin on spontaneous and evoked activity mimicked those of pyrilamine and cimetidine. Tetrodotoxin is known to be a very specific and potent blocker of voltage-dependent $\mathrm{Na}^{+}$channels (Cahalan, 1980; Catterall, 1986). In view of these considerations, it seems reasonable to conclude that the effects of antihistamines in the lateral line reflect primarily a local anestheticlike blockade of voltage-dependent $\mathrm{Na}^{+}$channels. Furthermore, since such channels are not thought to be present in hair cells (Konishi and Kelsey, 1968; Hudspeth, 1986) we suggest the site of action of pyrilamine and cimetidine is largely postsynaptic on the afferent nerve fibers. 

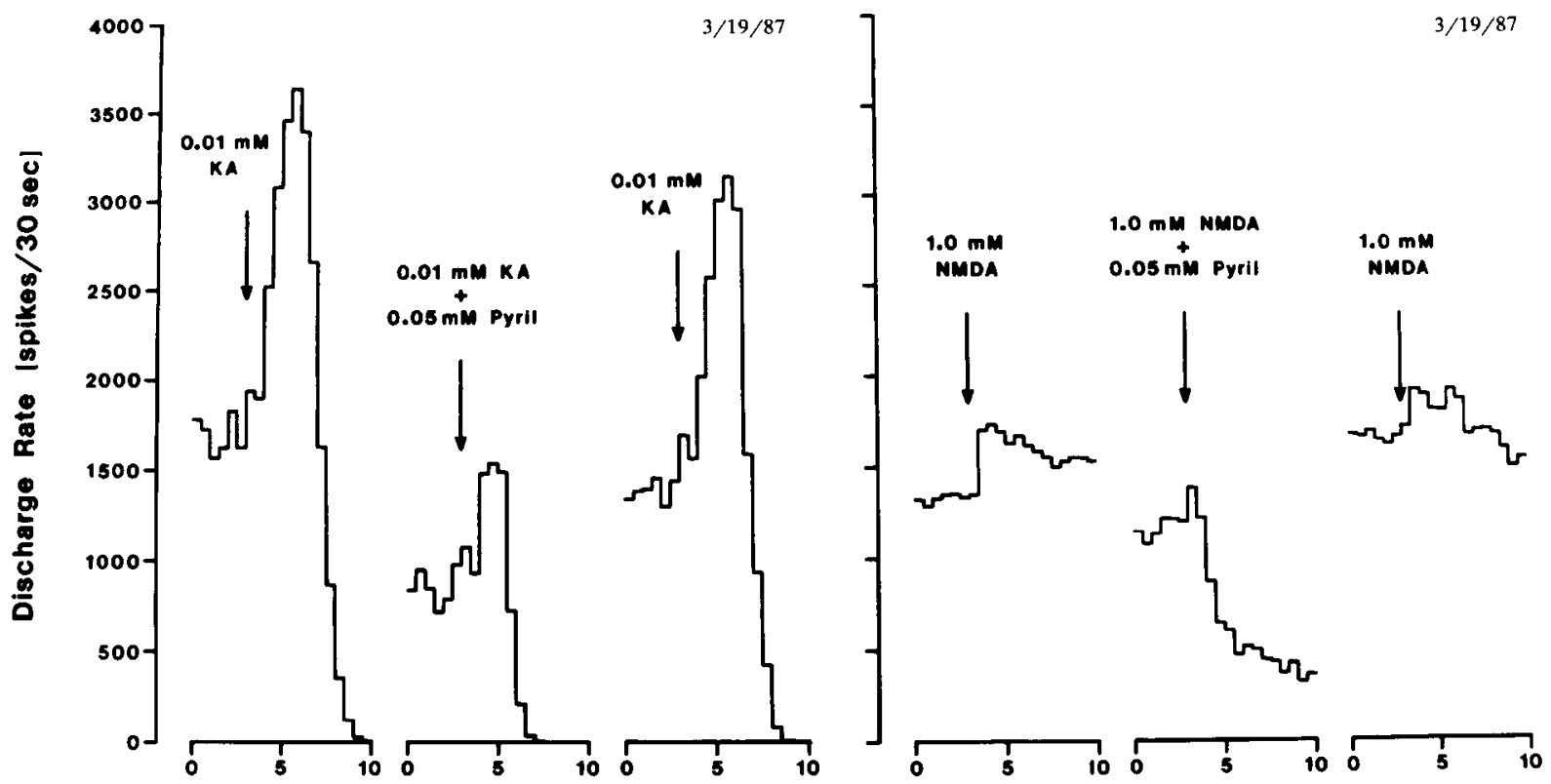

Minutes

Fig. 9. Responses of lateral line afferent nerve fibers to exogenously applied kannc acid (KA) and $N$-methyl-D-aspartate (NMDA) at indicated concentrations in the absence and presence of $0.05 \mathrm{mM}$ pyrilamine (Pyril). Arrow designation and experimental protocol as in Figs. 1 and 8. Response on the right in each panel was obtained after a 30 min drug-free Ringer wash. Data illustrate suppression of KA response and reversal of NMDA response from excitation to suppression. Note post-excitatory suppression to KA in the absence and presence of pyrilamine.

At near threshold concentrations, pyrilamine often had a small excitatory effect (Fig. 3). This may also be explained by actions on $\mathrm{Na}^{+}$channels. It is conceivable that the initial effect of pyrilamine is to open channels, producing an increased conductance of $\mathrm{Na}^{+}$ions to depolarize the nerve membrane. Alternatively, the same result could occur if pyrilamine inhibited channel closure. The open channels might then be more susceptible to blockade at higher concentrations of pyrilamine due to greater access of the drug to a binding site inside the channel.

Pyrilamine, at concentrations that suppressed spontaneous activity up to $90 \%$, selectively suppressed responses to high but not low levels of water motion (Fig. 5). Responses to high concentrations of L-glutamate were also markedly suppressed with responses to lower concentrations of L-glutamate being less affected or enhanced (Figs. 8 and 10). These results are suggestive of use-dependent blockade which is thought to be the classical mode of action of many local anesthetics
(Courtney, 1975; Strichartz, 1976; Calahan, 1980). In other words, agonist-induced depolarization leads to more frequent channel openings which increases the probability that channels will become blocked by anesthetic molecules. This would seem to add further support to the supposed local anesthetic-like activity of pyrilamine. However, one complication in this interpretation is the observation that tetrodotoxin also seemed to be more effective at suppressing responses to high but not low levels of water motion. Unlike most local anesthetics, tetrodotoxin binds to the outer opening of $\mathrm{Na}^{+}$channels and its actions are generally not thought to be dependent on whether the channels are open or closed (Strichartz, 1976; Cahalan, 1980). Thus, it is clear that further studies are needed to explain more fully the actions of histamine antagonists on water motion-induced excitation in the Xenopus lateral line.

The ability of antihistamines to depress nonspecifically responses to neuroactive substances other than histamine is well established. For ex- 


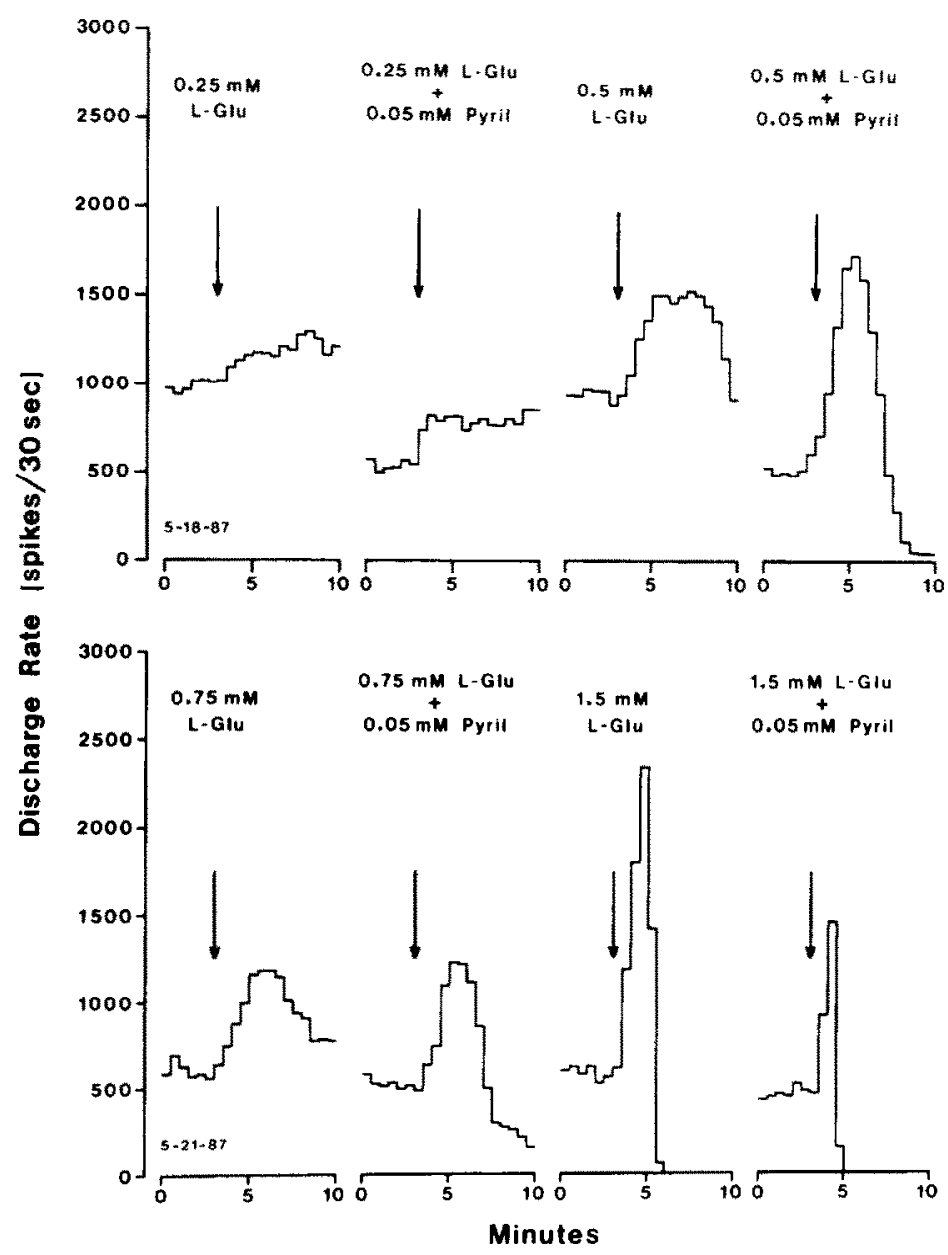

Fig. 10. Responses of lateral line afferent nerve fibers to exogenously applied L-glutamate (L-Glu) from two experiments (top and bottom panels) at indicated concentrations in the absence and presence of $0.05 \mathrm{mM}$ pyrilamine (Pyril). Arrow designation and experimental protocol as in Figs. 1 and 8. Data illustrate that the excitatory response to $1.5 \mathrm{mM}$ L-glutamate is suppressed by pyrilamine while the responses to lower concentrations of L-glutamate are unaffected or slightly enhanced. Note that the post-excitatory suppression induced by $1.5 \mathrm{mM} \mathrm{L-glutamate}$ appears unaffected by pyrilamine. Also, note the emergence of post-excitatory suppression at lower concentrations of L-glutamate $(0.5$ and $0.75 \mathrm{mM})$ in the presence of pyrilamine.

ample, antihistamines at sufficient concentrations have been shown to suppress responses to acetylcholine and catecholamines (Seithi et al., 1967; Phillis et al., 1968; Haas, 1974). In addition, suppression of glutamate-induced excitation has also been reported (Phillis et al., 1968). These actions have generally been attributed to the local-anesthetic activity of the histamine antagonists. However, there is evidence that other factors may be involved. For example, numerous studies have shown that antihistamines at low micromolar concentrations are capable of interacting with a variety of receptors other than those for histamine (Green and Hough, 1980; Green, 1983). Thus, studying the effects of pyrilamine and other $\mathrm{H}_{1}$-receptor antagonists on the amplitude and time course of endplate potentials in the sartorius muscle of frogs, Katayama and Tasaka (1985) concluded that antihistamines at $0.01-0.1 \mathrm{mM}$ inhibited the action of acetylcholine on its postsynaptic receptor and reduced the open time of receptor-coupled $\mathrm{Na}^{+}$channels. In addition, Constanti and Nistri (1976), studying the depression of glutamate-evoked depolarizations in lobster 
muscle fibers and the frog spinal cord, concluded that micromolar concentrations of antihistamines act as non-specific amino acid antagonists by interacting at the level of the receptor-coupled ionophores.

In the present study, pyrilamine exerted marked non-specific effects on amino acid-induced excitation. However, owing to the extracellular recording technique, it is not possible to distinguish conclusively between effects on voltage-dependent $\mathrm{Na}^{+}$channels at the level of nerve myelination and actions on postsynaptic glutamate receptorionophore complexes in the unmyelinated afferent terminals. Nevertheless, the fact that pyrilamine suppressed excitation to high concentrations of L-glutamate, L-aspartate, kainate and quisqualate without any apparent effect on the post-excitatory suppression induced by the excitants, suggests a primary action on voltage-dependent $\mathrm{Na}^{+}$channels at the level of nerve myelination. In this regard, a number of studies in other systems have shown that the excitatory response to L-glutamate and its analogues is often followed by a period of hyperpolarization and reduced action potential firing (Curtis et al., 1979; Peet et al., 1983; Hackman et al., 1987). There is considerable evidence that glutamate depolarization increases membrane permeability to $\mathrm{Na}^{+}, \mathrm{K}^{+}$and $\mathrm{Ca}^{2+}$ with the influx of $\mathrm{Ca}^{2+}$ predominantly linked to activation of NMDA receptors (Mayer and Westbrook, 1987). However, the mechanism underlying the post-excitatory suppression induced by excitatory amino acids is not clearly understood. In addition to a depolarization block, there is evidence that it may result from two other processes acting either alone or in concert. These are (1) activation of an electrogenic sodium pump by depolarizing influx of $\mathrm{Na}^{+}$(Ransom et al., 1975; Segal, 1981; Padjen and Smith, 1983) and (2) activation of $\mathrm{a} \mathrm{Ca}^{2+}$-dependent $\mathrm{K}^{+}$efflux subsequent to $\mathrm{Ca}^{2+}$ influx (Nicoll and Alger, 1981). It is not known which mechanism is involved in the generation of postexcitatory suppression in the lateral line. However, the fact that the suppression occurred even though amino acid-induced excitation was reduced suggests the mechanisms underlying the generation of suppression are unaffected by pyrilamine. Thus, it is possible that pyrilamine acts on voltage-dependent $\mathrm{Na}^{+}$channels to reduce the ability of the lateral-line nerve fibers to fire action potentials in response to membrane depolarization but does not affect the conductance mechanisms associated with excitatory amino acid receptors on the afferent terminals. This possibility receives support from the action of tetrodotoxin which also reduced the excitation to high concentrations of L-glutamate without affecting the occurrence of post-excitatory suppression. In other systems, tetrodotoxin, at concentrations sufficient to block the generation of action potentials, does not affect the depolarizing action of L-glutamate measured with intracellular recordings (Zieglgansberger and Puil, 1972). It should also be noted that the ability of pyrilamine and tetrodotoxin to block post-excitatory suppression contrasts with the actions of excitatory amino acid receptor antagonists in the lateral line (Bledsoe and Bobbin, 1982; Bledsoe et al., 1985). These compounds reduce both the excitation and suppression induced by high concentrations of L-glutamate; an action that would be anticipated if the block of glutamate depolarization occurs at the level of its receptors. This adds further support to the suggestion that pyrilamine has its primary action at a site other than postsynaptic glutamate receptors.

Although the effects of pyrilamine on amino acid-induced responses can be interpreted in terms of a local anesthetic blockade of voltage-dependent $\mathrm{Na}^{+}$channels, one observation suggests that actions at the level of receptor-coupled ionophores cannot be fully excluded. Thus, it is unclear how the excitation produced by NMDA was reversed to suppression by pyrilamine. If the conductance mechanisms associated with this type of glutamate receptor were unaffected then one would expect that the local anesthetic effects of pyrilamine would again simply prevent the nerve fibers from generating action potentials in response to membrane depolarization occurring at the afferent terminals. A suppression, without reversal, of the NMDA response was produced by tetrodotoxin. This suggests that the mechanism of action of pyrilamine includes an additional component that may be specifically associated with the NMDA receptor-ionophore complex.

It is well established that the NMDA receptor and its associated ion channel exhibit several unique properties that distinguish it from the other 
types of glutamate receptors (Ascher and Nowak, 1987; Kemp et al., 1987; MacDermott and Dale, 1987; Mayer and Westbrook, 1987). For example, unlike kainate and quisqualate receptors, the current changes associated with NMDA receptor activation are longer in duration and include a large $\mathrm{Ca}^{2+}$ component in addition to increased permeability to $\mathrm{Na}^{+}$and $\mathrm{K}^{+}$(Ascher and Nowak, 1987). The activation of NMDA receptors is also highly voltage-dependent due to a voltage-dependent block by magnesium (MacDermott and Dale, 1987). In addition, the NMDA receptor-coupled ionophore is susceptible to use-dependent blockade in a non-competitive, voltage-dependent manner by phencyclidines, sigma opiates and other compounds (Kemp et al., 1987). Thus, there are a number of possible explanations for the effect of pyrilamine on responses to NMDA. For example, it is conceivable that the conductance changes associated with NMDA-receptor activation are more susceptible to subtle changes in membrane potential that may have been induced by pyrilamine. In this regard, it is of interest that Constanti and Nistri (1976) reported that pyrilamine altered conductance and produced small changes in the resting membrane potential of lobster muscle fibers. In addition, it is possible that the NMDA receptor-ionophore complex is more susceptible to a non-competitive blockade by pyrilamine. The reversal of the NMDA response by pyrilamine may also reflect a differential block of $\mathrm{Na}^{+}$but not $\mathrm{Ca}^{2+}$ currents leading to hyperpolarization from a $\mathrm{Ca}^{2+}$-stimulated efflux of $\mathrm{K}^{+}$. At low concentrations, L-glutamate exerts a substantial portion of its action through activation of NMDA receptors (Mayer and Westbrook, 1987). Thus, a similar $\mathrm{K}^{+}$conductance might explain the appearance of post-excitatory suppression to low concentrations of L-glutamate in the presence of pyrilamine (Fig. 10). Although the results on amino acid responses lend further support to the conclusion that pyrilamine acts in a non-specific manner, it is clear that additional studies are needed to determine which of the above possibilities might contribute to the mode of action of histamine antagonists in the Xenopus lateral line.

In conclusion, the results of this study do not support the suggestion that histamine functions as a neurotransmitter or modulator in hair-cell sys- tems. Although a species difference could account for the reported effects of histamine in the semicircular canal, the possibility of non-specific actions of histamine has to be considered. Along these lines, histamine has been shown to suppress non-specifically responses to excitatory amino acids in the central nervous system (Phillis et al., 1968; Haas, 1981). Finally, it should be emphasized that results obtained in hair-cell systems with micromolar concentrations of histamine antagonists should be interpreted with caution due to their known local anesthetic effects and actions on receptors other than those for histamine.

\section{Acknowledgements}

This research was supported by a Program Project Grant (NS-05785) from the National Institutes of Health.

\section{References}

Ascher, P. and Nowak, L. (1987) Electrophysiological studies of NMDA receptors. Trends Neurosci. 10, 284-288.

Bledsoe, S.C., Jr. (1986) Pharmacology and neurotransmission of sensory transduction in the inner ear. In: J. Miller (Ed.), Seminars in Hearing, vol. 7. Thieme, Inc., New York, pp. $117-138$.

Bledsoe, S.C., Jr. and Bobbin, R.P. (1982) Effects of D- $\alpha-$ amino-adipate on excitation of afferent fibers in the lateral line of Xenopus laevis. Neurosci. Lett. 32, 315-320.

Bledsoe, S.C.. Jr., Bobbin, R.P. and Puel, J.-L. (1988) Neurotransmission in the inner ear. In: A.F. Jahn and J.R. Santos-Sacchi (Eds.), Physiology of Hearing, Raven Press, New York, pp. 385-406.

Bledsoe, S.C., Jr., Chihal, D.M., Bobbin, R.P. and Morgan, D.N. (1983) Comparative actions of glutamate and related substances on the lateral line of Xenopus laevis. Comp. Biochem. Physiol. 75C, 119-206.

Bledsoe, S.C., Jr., Meyer, J.R. and Howland, M.M. (1985) Effects of excitatory amino acid receptor antagonists on synaptic excitation in the lateral line of Xenopus laevis. Assoc. Res. Otolaryngol. Abstr. 8, 111.

Bledsoe, S.C., Jr. and Sinard, R. (1987) Action of histamine and histamine antagonists on activity of afferent nerve fibers in the Xenopus lateral line. Soc. Neurosci. Abstr. 13. 1471.

Bobbin, R.P., Bledsoe, S.C., Jr., Winbery, S. Caesar, G. and Jenison, G.L. (1985a) Comparative actions of GABA and acetylcholine on the Xenopus laevis lateral line. Comp. Biochem. Physiol. 80C, 313-318.

Bobbin, R.P., Bledsoe, S.C., Jr., Winbery, S.L. and Jenison, G.L. (1985b) Actions of putative neurotransmitters and other relevant compounds on Xenopus laevis lateral line. 
In: D.G. Drescher (Ed.), Auditory Biochemistry, Charles C. Thomas, Springfield, pp. 102-122.

Bobbin, R.P. and Thompson, M.H. (1978) Effects of putative transmitters on afferent cochlear transmission. Ann. Otol. Rhinol. Laryngol. 87, 185-190.

Borchard, U., Hafner, D. and Hirth, C. (1986) Electrophysiological actions of histamine and $\mathrm{H}_{1^{-}}, \mathrm{H}_{2}$-receptor antagonists in cardiac tissue. Agents Actions 18, 186-190.

Cahalan, M. (1980) Molecular properties of sodium channels in excitable membranes. In: C.W. Cotman, G. Poste and G.L. Nicholson (Eds.), The Cell Surface and Neuronal Function, Elsevier, Amsterdam, pp. 1-47.

Catterall, W.A. (1986) Molecular properties of voltage-sensitive sodium channels. Ann. Rev. Biochem. 55, 953-985.

Constanti, A. and Nistri, A. (1976) Antagonism by some antihistamines of the amino acid-evoked responses recorded from the lobster muscle fiber and the frog spinal cord. $\mathrm{Br}$. J. Pharmacol. 58, 583-592.

Courtney, K.R. (1975) Mechanism of frequency-dependent inhibition of sodium currents in frog myelinated nerve by the lidocaine derivative GEA 968. J. Pharmacol. Exp. Ther. $195,225-236$.

Curtis, D.R., Lodge, D. and McLennan, H. (1979) The excitation and depression of spinal neurones by ibotenic acid. J. Physiol. (London) 291, 19-28.

Geller, H.M. (1981) Histamine actions on activity of cultured hypothalamic neurons: evidence for mediation by $\mathrm{H}_{1}$ and $\mathbf{H}_{2}$-histamine receptors. Develop. Brain Res. 1, 89-101.

Green, J.P. (1983) Histamine receptors in brain. In: L.L. Iversen, S.D. Iversen and S.H. Snyder (Eds.), Handbook of Psychopharmacology, Vol. 17, Biochemical Studies of CNS Receptors, Plenum Press, New York, pp. 385-420.

Green, J.P. and Hough, L.B. (1980) Histamine receptors. In: D. Schulster and A. Levitzki (Eds.), Cellular Receptors for Hormones and Neurotransmitters, John Wiley, New York, pp. 287-305.

Hackman, J.C., Holohean, A.M., Wohlberg, C.J. and Davidoff, R.A. (1987) After-hyperpolarizations produced in frog motoneurons by excitatory amino acid analogues. Brain Res. 407, 94-101.

Ilaas, II.L. (1974) Ilistamine: action on single hypothalamic neurons. Brain Res. 76, 363-366.

Haas, H.L. (1981) Histamine and the central nervous system: analysis of histamine actions by intra- and extracellular recording in hippocampal slices of the rat. Agents Actions $11,125-128$.

Hudspeth, A.J. (1986) The ionic channels of a vertebrate hair cell. In: A. Flock and J. Wersall (Eds.), Cellular Mechanisms in Hearing, Elsevier, Amsterdam, pp. 21-27.

Katayama, S. and Tasaka, K. (1985) Effects of $\mathrm{H}_{1}$-receptor blocking drugs on the frog sartorius neuromuscular junction. Br. J. Pharmacol. 85, 747-753.
Kemp, J.A., Foster, A.C. and Wong, E.H.F. (1987) Non-competitive antagonists of excitatory amino acid receptors. Trends Neurosci. 10, 294-298.

Konishi, T. and Kelsey, E. (1968) Effect of tetrodotoxin and procaine on cochlear potentials. J. Acoust. Soc. Am. 43, 471-480.

MacDermott, A.B. and Dale, N. (1987) Receptors, ion channels and synaptic potentials underlying the integrative actions of excitatory amino acids. Trends Neurosci. 10, 280-284.

Mayer, M.L. and Westbrook, G.L. (1987) The physiology of excitatory amino acids in the vertebrate central nervous system. Prog. Neurobiol. 28, 197-276.

Nicol, R.A. and Alger, B.E. (1981) Synaptic excitation may activate a calcium-dependent potassium conductance in hippocampal pyramidal cells. Science 212, 957-959.

Norris, C.H., Guth, P.S. and Quine, D.B. (1987) The effects of histamine on the semicircular canal of the frog. Assoc. Res. Otolaryngol. Abstr. 10, 107.

Orsetti, M. and Sorba, G. (1988) Pharmacological profile to new histamine $\mathrm{H}_{2}$-receptor antagonists related to cimetidine, ranitidine and lamtidine. J. Pharm. Pharmacol. 40, 31-34.

Padjen, A.L. and Smith, P.A. (1983) The role of the electrogenic sodium pump in the glutamate afterhyperpolarization of frog spinal cord. J. Physiol. (London) 336, 433-451.

Peet, M.J., Malik, R. and Curtis, D.R. (1983) Post-excitatory depression of neuronal firing by acidic amino acids and acetylcholine in the cat spinal cord. Brain Res. 263, 162-166.

Phillis, J.W., Tebecis, A.K. and York, D.H. (1968) Histamine and some antihistamines: their actions on cerebral cortical neurones. Br. J. Pharmac. Chemother. 33, 426-440.

Ransom, B.R., Barker, J.L. and Nelson, P.G. (1975) Two mechanisms for poststimulus hyperpolarizations in cultured mammalian neurones. Nature (London) 256, 424-425.

Segal, M. (1981) The actions of glutamic acid on neurons in the rat hippocampal slice. In: G. Di Chiara and G.L. Gessa (Eds.), Glutamate as a Neurotransmitter, Raven Press, New York, pp. 217-225.

Sethi, O.P., Gulati, O.D., Gokhale, S.D. and Joseph, A.D. (1967) Modification of adrenergic responses by antazoline and mepyramine. Archs Int. Pharmacodyn. Ther. 168, 64-81.

Strichartz, G. (1976) Molecular mechanisms of nerve block by local anesthetics. Anesthesiology 45, 421-441.

Taylor, J.E., Yaksh, T.L. and Richelson, E. (1982) Histamine $H_{1}$ receptors in the brain and spinal cord of the cat. Brain Res. 243, 391-394.

Zieglgansberger, W. and Puil, E.A. (1972) Tetrodotoxin interference of CNS excitation by glutamic acid. Nature New Biol. 239, 204-205. 